\title{
Soil Structure and Porous System in Response to Plant Components of an Agrosilvopastoral System
}

\author{
Carla Danielle Vasconcelos do Nascimento ${ }^{1}$, Mirian Cristina Gomes Costa ${ }^{1}$, Raul Shiso Toma ${ }^{1}$, \\ Jaedson Claúdio Anunciato Mota ${ }^{1}$, Ademir Silva Menezes ${ }^{1} \&$ Miguel Cooper $^{2}$ \\ ${ }^{1}$ Department of Soil Sciences, Federal University of Ceará, Fortaleza, Ceará, Brazil \\ ${ }^{2}$ Department of Soil Science, Luiz de Queiroz College of Agriculture, São Paulo, Brazil \\ Correspondence: Carla Danielle Vasconcelos do Nascimento, Department of Soil Sciences, Federal University of \\ Ceará, Fortaleza, Ceará, Brazil. E-mail: carla@agronoma.eng.br
}

Received: January 10, 2018

Accepted: February 24, 2018

Online Published: April 15, 2018

doi:10.5539/jas.v10n5p63

URL: https://doi.org/10.5539/jas.v10n5p63

\begin{abstract}
Production systems of agroecological nature, such as agrosilvopastoral systems, have been considered as beneficial in various regions of the world. In semi-arid regions, these systems can contribute not only to food production, but also to soil conservation. Considering the specificities of each plant component, it is supposed that there is a different influence on soil structure, so that some components can be more efficient than others in the improvement of this structure. In the present study, the objective was to evaluate physical attributes with emphasis on the pore distribution, shape and size of a Luvisol in the influence area of different plant components of an agrosilvopastoral system in the semi-arid region of the Ceará state. The study was carried out in an agrosilvopastoral system established in the municipality of Sobral (Ceará, Brazil), with a completely randomized strip-plot design and four replicates. The treatments corresponded to three plant components: arbustive (Leucaena leucocephala), arboreal (Poincianella pyramidalis) and agricultural (Zea mays); and four soil layers: $0.0-0.05,0.05-0.18,0.18-0.25$ and $0.025-0.41 \mathrm{~m}$. For physical and micromorphometric analyses, undisturbed soil samples were collected in profiles in the areas covered by the plant components. The following attributes were analyzed: soil density, soil-air intrinsic permeability, soil-water characteristic curve, total porosity and pore distribution by shape and size. The soil under the influence of the components L. leucocephala and $P$. pyramidalis showed better structure, represented by the lower values of density, higher intrinsic permeability to the air and larger total area of pores, in comparison to the soil under the influence of Zea mays. The unfavorable result of the annual crop is due not only to the plant component, but also to the grazing of crop residues in the management system.
\end{abstract}

Keywords: analysis of images, multi-species agroecosystem, soil aggregation, soil porosity

\section{Introduction}

Semi-arid regions have poorly developed soils, which are minerally rich, little thick and with reduced water retention capacity (Verheye, 2009). The edaphoclimatic conditions of these regions hamper agricultural production and, when combined with inadequate management practices - such as overgrazing, favor the degradation of the soils through erosion (Van Oudenhoven et al., 2015).

Agrosilvopastoral systems deserve attention as a viable alternative for food production combined with environmental conservation in semi-arid agroecosystems. These systems constitute practices planned to obtain benefits from the interaction between their components. They consist in the cultivation of trees, crops and, sometimes, animal raising in a combination that interacts and results in more complex land use systems, with higher efficiency to capture and use resources, in comparison to the conventional land use (Silva, 2011).

These systems may play an important role in the improvement of soil fertility by supplying organic carbon, increasing $\mathrm{N}$ entry through its fixation, reduction in soil loss by erosion, cycling nutrients through litter and recovering nutrients from deeper soil horizons. Agrosilvopastoral systems differ from monoculture systems mainly because they benefit from the ability of each plant species in the acquisition and cycling of nutrients (Buyer et al., 2017). 
Soil structure represents one of the main indicators of soil physical quality. Water retention, water movement, root development, gas diffusion and good conditions for soil biota are related to the soil porous system (Pires et al., 2017). In order to recommend species to compose agrosilvopastoral systems in degraded soils of the semi-arid region, it is important to understand if there are plant components with greater contribution to the improvement of soil structure.

In agrosilvopastoral system, the tree component influences most characteristics of the pasture, according to its distance to the row of trees (Paciullo et al., 2011). Trees often have deep root system and produce more residues than the other types of vegetation cover, increasing the organic matter content of the soil and improving its water retention. This also increases soil porosity and facilitates water infiltration (Ilstedt et al., 2007).

Trees help recover nutrients, conserve soil moisture and improve soil organic matter (Duguma \& Hager, 2011). According to Nguyen (2013), using multifunctional trees and integrated approaches can improve the profitability of agroforestry systems. Thus, an increasing scientific challenge is related to methods and tools to evaluate useful trees in various human and ecological contexts. The presence of trees, along with minimum soil disturbance, improves most soil properties, such as organic matter contents, aggregation, water infiltration and reduces density (Romaneckas et al., 2009). Under minimum cultivation conditions, as in agrosilvopastoral systems, the soil has a more continuous system of macropores, which may be favored by the biopores created by the perennial vegetation. Therefore, native vegetation positively interferes with the soil (Salako \& Kirchhof, 2003).

The crops most used in agrosilvopastoral systems can also favor soil structure. Regarding grasses, they contribute to processes of formation and stabilization of aggregates. This occurs because the high root density brings soil particles closer through the constant absorption of water from the soil, and also because there is constant renewal of the root system and uniform distribution of the organic exudates in the soil, which stimulate microbial activity, whose byproducts also act in the stabilization of the aggregates (Ola et al., 2015). Soil cover plants (especially herbaceous) represent a barrier that limit the impact of rainfall on the soil, which result in a decrease in the detachment and transport of particles (Béliveau et al., 2017). On the other hand, the management of annual crops in agrosilvopastoral systems can compromise soil structure. In crop-livestock integration systems, it was observed that the compaction caused by the grazing of crop residues is a constant concern of the producers. This concern is well-founded, especially if the system is not adequately managed (Sulc \& Franzluebbers, 2014).

Parameters such as pore size distribution, pore shape and relative position of aggregates and pores are very important for evaluation of soil structure modifications induced, for example, by different management practices (Pagliai et al., 1989). Image analysis is used to determine pore size and distribution (Stoops, 2003). It is carried out using thin sections or soil blocks to quantify porous space structure, pore distribution and characterize irregularities, orientation, shape and size of pores. This technique is based on the impregnation of a dry soil sample with resin and fluorescent pigment (Murphy et al., 1977). Soil blocks are photographed and the images are analyzed in an image analysis software. 2-D images provide information on the number, area, perimeter, diameter, shape, arrangement and size distribution of pores.

Measurements of pore size distribution, shape and arrangement provide elements that enable a more detailed knowledge on the soil in agrosilvopastoral systems, allowing to characterize the structural differences caused by the plant components. Although the relationship between the type of pores and their functionality is well established, studies on the characterization of the porous systems of soils under vegetation covers in these systems are still scarce.

The present study assumed the hypothesis that the plant components in agrosilvopastoral system lead to structural differences in the soil and the trees are responsible for the greatest porosity, permeability and better pore distribution, especially in the superficial layers. Thus, the objective was to characterize the morphology of pores and physical functioning of the soil under the influence of three types of vegetation cover (arboreal—Poincianera pyramidalis, arbustive—Leucaena leucocephala and agricultural—Zea mays) in four soil layers under agrosilvopastoral system in the Brazilian semi-arid region.

\section{Material and Methods}

\subsection{Location and Characterization of the Studied Area}

The study was carried out in an agrosilvopastoral system of the Embrapa Goats and Sheep, located in the municipality of Sobral (Ceará, Brazil). The municipality is in the semi-arid region $\left(3^{\circ} 41^{\prime} \mathrm{S} ; 40^{\circ} 20^{\prime} \mathrm{W}\right.$; at altitude of $69 \mathrm{~m}$ ) and has BShw' climate according to Köppen's classification, with rainy season from January to May. 
The soil was classified as Chromic Luvisol (FAO, 2006), in which pits were opened, one for each plant component to be evaluated, at a distance of $0.2 \mathrm{~m}$ from the stem of each component. Soil samples collected in the horizons of each profile were analyzed for granulometry, clay dispersed in water, flocculation degree, assimilable phosphorus and organic carbon (Table 1), determined in four replicates. The profiles were morphologically described (Table 2).

Table 1. Granulometry, clay dispersed in water (CDW), flocculation degree (FD), assimilable phosphorus (P) and organic carbon (OC) of soil profiles under the influence of three components of the agrosilvopastoral system (Leucaena leucocephala, Poincianella pyramidalis and Zea mays) in the Brazilian semi-arid region

\begin{tabular}{|c|c|c|c|c|c|c|c|c|}
\hline Symb. Horiz. & Depths & Sand & Silt & Clay & CDW & FD & $\mathrm{P}$ & $\mathrm{OC}$ \\
\hline & -------- $\mathrm{m}$-- & ------. & -------- & kg ----- & ------------ & ---- \% ---- & -- mg/kg -- & $--\mathrm{g} / \mathrm{kg}-$ \\
\hline \multicolumn{9}{|c|}{ Leucaena leucocephala } \\
\hline A1 & $0.00-0.05$ & 736.5 & 224.9 & 38.6 & 24.4 & 36.8 & 116.8 & 13.0 \\
\hline $\mathrm{A} 2$ & $0.05-0.18$ & 738.5 & 210.1 & 51.4 & 37.4 & 27.2 & 86.7 & 4.9 \\
\hline Bt1 & $0.18-0.25$ & 600.0 & 191.4 & 208.6 & 139.2 & 33.3 & 23.3 & 3.5 \\
\hline Bt2 & $0.25-0.41$ & 540.0 & 170.4 & 289.6 & 144.8 & 50.0 & 20.0 & 3.2 \\
\hline $\mathrm{Bt} 3$ & $0.41-0.57$ & 561.0 & 148.8 & 290.2 & 159.6 & 45.0 & 22.4 & 2.3 \\
\hline $\mathrm{BC} 1$ & $0.57-0.67$ & 565.5 & 177.3 & 257.2 & 138.0 & 46.3 & 21.9 & 2.2 \\
\hline $\mathrm{BC} 2$ & $0.67-0.90^{+}$ & 577.0 & 194.2 & 228.8 & 135.6 & 40.7 & 18.1 & 1.3 \\
\hline \multicolumn{9}{|c|}{ Poincianera pyramidalis } \\
\hline A1 & $0.00-0.05$ & 753.0 & 171.2 & 75.8 & 26.6 & 64.9 & 44.2 & 13.3 \\
\hline $\mathrm{A} 2$ & $0.05-0.18$ & 746.5 & 180.9 & 72.6 & 41.0 & 43.5 & 10.0 & 5.1 \\
\hline Bt1 & $0.18-0.25$ & 699.0 & 186.4 & 114.6 & 61.4 & 46.4 & 4.5 & 3.7 \\
\hline Bt2 & $0.25-0.41$ & 622.0 & 126.6 & 251.4 & 145.4 & 42.2 & 4.9 & 3.3 \\
\hline $\mathrm{Bt} 3$ & $0.41-0.57$ & 595.0 & 93.6 & 311.4 & 160.2 & 48.5 & 0.3 & 2.9 \\
\hline $\mathrm{BC} 1$ & $0.57-0.67$ & 625.5 & 136.1 & 238.4 & 125.6 & 47.3 & 0.6 & 2.2 \\
\hline $\mathrm{BC} 2$ & $0.67-0.90^{+}$ & 650.0 & 131.0 & 219.0 & 114.8 & 47.6 & 0.6 & 1.5 \\
\hline \multicolumn{9}{|l|}{ Zea mays } \\
\hline A1 & $0.00-0.05$ & 715.5 & 211.1 & 73.4 & 28.2 & 61.6 & 33.5 & 10.4 \\
\hline $\mathrm{A} 2$ & $0.05-0.18$ & 672.6 & 210.0 & 117.4 & 70.8 & 39.7 & 7.3 & 5.2 \\
\hline A3 & $0.18-0.25$ & 676.5 & 235.3 & 88.2 & 57.6 & 34.7 & 10.9 & 6.6 \\
\hline Bt1 & $0.25-0.41$ & 501.0 & 198.0 & 301.0 & 169.8 & 43.6 & 2.9 & 3.5 \\
\hline Bt2 & $0.41-0.65$ & 593.5 & 222.7 & 183.8 & 126.8 & 31.0 & 5.7 & 4.6 \\
\hline $\mathrm{BC}$ & $0.65-0.85^{+}$ & 652.7 & 210.7 & 136.6 & 102.5 & 25.0 & 2.5 & 2.5 \\
\hline
\end{tabular}

Note. Symb. Horiz.: Symbology of the soil horizons. 
Table 2. Morphological description (structure, texture, wet color, roots and biological activity) of the soil profiles under the influence of three plant components (Leucaena leucocephala, Poincianella pyramidalis and Zea mays) in an agrosilvopastoral system in the Brazilian semi-arid region.

\begin{tabular}{|c|c|c|c|c|c|}
\hline Horizons/depth (m) & Structure & Texture & Wet color (Munsell) & Roots & Biological activity/porosity \\
\hline \multicolumn{6}{|c|}{ Leucaena leucocephala } \\
\hline A1 (0.0-0.05) & $2 \mathrm{M} \mathrm{BS}$ & Sandy loam & 7,5 YR 4/2 & Abundant & Cavities and canals \\
\hline A2 (0.05-0.18) & $1 \mathrm{P}-\mathrm{M}$ BS & Sandy loam & 7,5YR 5/4 & Abundant & Canals with filling \\
\hline $\operatorname{Bt1}(0.18-0.25)$ & $2 \mathrm{M} P R$ & Sandy clay loam & 2,5 YR 5/6 & Common & Canals with filling \\
\hline Bt2 (0.25-0.41) & $2 \mathrm{M} \mathrm{PR}$ & Sandy clay loam & $10 \mathrm{R} 4 / 8$ & Common & Tubular pores \\
\hline $\mathrm{Bt} 3(0.41-0.57)$ & 2 P-M PR & Sandy clay loam & $2,5 \mathrm{YR} 5 / 3$ & Common & Tubular pores \\
\hline BC1 (0.57-0.67) & 3 M-G PR & Sandy clay loam & 2,5 YR 7/4 & Common & Tubular pores \\
\hline BC2 (0.67-0.90) & 3 M-G PR & Sandy clay loam & $2,5 \mathrm{YR} 6 / 1$ & Common & Tubular pores \\
\hline \multicolumn{6}{|c|}{ Poincianera pyramidalis } \\
\hline A1 $(0.0-0.05)$ & 1 P-M BS & Sandy loam & $7,5 \mathrm{YR} 4 / 2$ & Common & Tubular pores \\
\hline A2 (0.05-0.18) & $1 \mathrm{P}-\mathrm{M}$ BS & Sandy loam & $7,5 \mathrm{YR} 5 / 4$ & Common & Galleries, tubules and earthworms \\
\hline $\operatorname{Bt1}(0.18-0.25)$ & $2 \mathrm{M}$ PR & Sandy clay & 2,5 YR 5/6 & Common & Earthworms \\
\hline $\mathrm{Bt} 2(0.25-0.41)$ & $2 \mathrm{M}-\mathrm{G} P R$ & Sandy clay loam & $10 \mathrm{R} 4 / 8$ & Few & Earthworms \\
\hline Bt3 $(0.41-0.57)$ & 2 P-M PR & Sandy clay loam & 2,5 YR 5/3 & Common & Earthworms \\
\hline BC1 (0.57-0.67) & 3 M-G PR & Sandy clay loam & 2,5 YR $6 / 4$ & Common & Fissural pores \\
\hline BC2 (0.67-0.90) & 3 M-G PR & Sandy clay loam & $2,5 \mathrm{YR} 5 / 2$ & Few & Fissural pores \\
\hline \multicolumn{6}{|l|}{ Zea mays } \\
\hline A1 (0.0-0.05) & $2 \mathrm{M} \mathrm{BS}$ & Sandy loam & 7,5 YR 3/4 & Common & Canals with filling \\
\hline A2 (0.05-0.18) & 2 P-M BS & Sandy loam & 7,5 YR 4/4 & Common & Canals with filling \\
\hline A3 (0.18-0.25) & $2 \mathrm{M} \mathrm{BS}$ & Sandy clay loam & $5 \mathrm{YR} 4 / 4$ & Common & Fissural pores \\
\hline Bt1 (0.25-0.41) & $2 \mathrm{M}-\mathrm{G} P \mathrm{PR}$ & Sandy clay loam & $5 Y R 4 / 6$ & Common & Fissural pores \\
\hline $\mathrm{Bt} 2(0.41-0.65)$ & $2 \mathrm{M}-\mathrm{G} P R$ & Sandy clay loam & $2 \mathrm{YR} 3 / 6$ & Few & Fissural pores \\
\hline $\mathrm{BC}(0.65-0.85)$ & 3 G PR & Sandy clay loam & 7,5YR 5/6 & Few & Fissural pores \\
\hline
\end{tabular}

Note. *Structure: 1-weak; 2-moderate; 3-strong; S: small, M: medium, L: large; SB: Subangular blocky, PR: Prismatic; Z: depths.

The agrosilvopastoral system where the study was conducted occupies an 8-ha area. It was installed in 1997, preserving the native arboreal vegetation cover of $22 \%$, represented by species such as Poincianella pyramidalis and Auxemma oncocalyx. Since the ASPS (agrosilvopastoral system) was installed, the area has been manually prepared and planted with maize (Zea mays) every year, in 3.0-m-wide strips, separated by rows of leguminous crops that were established in the system, such as Leucaena leucocephala (Figure 1). 


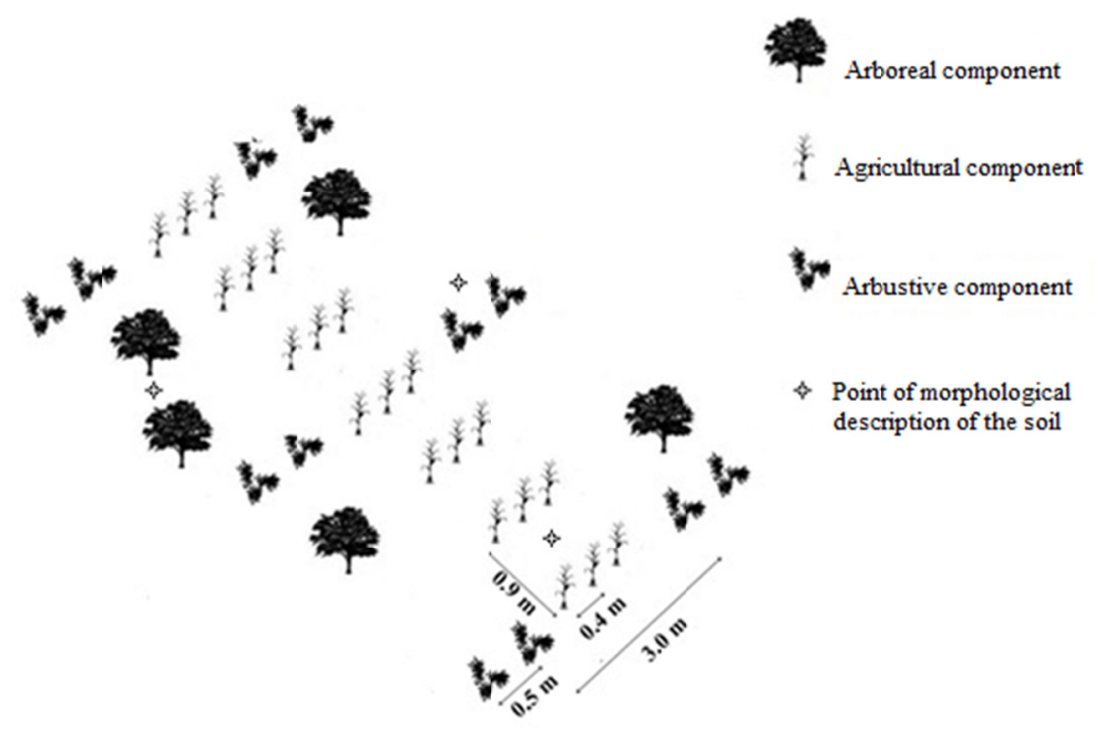

Figure 1. Representation of the Agrosilvopastoral System in the semi-arid region of Sobral, CE, Brazil

The species Leucaena leucocephala of the agrosilvopastoral system is used as a protein bank for goats and sheep in the dry period. In 2014, pruning residues of Leucaena leucocephala were deposited on the soil, in the spaces between the double rows of the leguminous species, which is the area intended for maize cultivation.

Inside the agrosilvopastoral system, the soil influenced by the following species was evaluated: Zea mays (crop component) - characterizes an important food crop in ASPS in the semi-arid region; Leucaena leucocephala - tree-shrub component, exotic and with favorable potential to be introduced in ASPS in the semi-arid region, for being a leguminous species and having importance as forage; Poincianella pyramidalis ('Catingueira') - tree component native to the semi-arid region, with important contribution to the cycling of nutrients in an ASPS.

\subsection{Experimental Design and Sampling}

Soil physical attributes were evaluated using a completely randomized strip-plot design, with four replicates. The evaluated treatments were three plant components: arbustive (Leucaena leucocephala), arboreal (Poincianella pyramidalis) and agricultural (Zea mays), and four soil layers: 0.0-0.05, 0.05-0.18, 0.18-0.25 and 0.25-0.41 m.

For physical analyses, undisturbed samples were collected in the previously described profiles, in the four studied layers, with four replicates. These samples were collected in $100 \mathrm{~cm}^{3}$ volumetric rings, vertically in relation to the plane of the terrain. After the collection, the samples were packed and sent to the Laboratory of Soil Physics of the Federal University of Ceará for the analyses.

The samples for image analysis of the main horizons detected in the morphological description were collected in the three profiles, in three layers $(0.0-0.12 \mathrm{~m} ; 0.14-0.26 \mathrm{~m}$ and $0.30-0.42 \mathrm{~m})$ established according to the dimensions of the paper card boxes used in the collection $(0.07 \times 0.05 \times 0.12 \mathrm{~m})$. The collection boxes were oriented to the surface for the sampling.

\subsection{Analyzed Physical Attributes}

Soil density was determined through the volumetric ring method using undisturbed soil samples, collected in cylinders of known volume and dried at $105^{\circ} \mathrm{C}$ until constant weight (Blake \& Hartge, 1986).

Soil-air intrinsic permeability was determined according to the principle of the decreasing pressure method (Kirkham, 1946). An amount of air corresponding to the pressure of $1 \mathrm{kPa}$ in the reservoir was passed through a volumetric ring containing the undisturbed soil sample, with water in equilibrium for the tensions of 2, 6, 10, 33 and $300 \mathrm{kPa}$. The air permeability coefficient $\left(\mathrm{K}_{\text {air }}\right)$ was determined through Equation 1:

$$
K_{a r}=\frac{L \eta V}{A P_{\text {atm }}} \times|S|
$$

where, $K_{\text {air }}$ is the air permeability coefficient $\left(\mathrm{m}^{2}\right), \mathrm{V}$ is the volume of air passing through the cylinder $\left(\mathrm{m}^{3}\right), \eta$ is the dynamic viscosity of the air (Pa.s), L is the height of the volumetric ring (m), A is the transverse section of 
the soil sample $\left(\mathrm{m}^{2}\right), \mathrm{P}_{\mathrm{atm}}$ is the local atmospheric pressure $(\mathrm{Pa})$ and $\mathrm{S}$ is the angular coefficient of the linear regression of the pressure (ln of pressure) as a function of time.

The soil-water characteristic curves were determined in the layers of $0.0-0.05,0.05-0.18,0.18-0.25$ and $0.25-0.41 \mathrm{~m}$ of each soil profile, in undisturbed soil samples collected in volumetric rings. Gravimetric water content was obtained using the Haines' funnel for the points of low matric potentials $(-0,-2,-4,-6,-8$ and -10 $\mathrm{kPa})$ and Richards' pressure plate apparatus for the other potentials $(-33,-100,-300$ and $-1,500 \mathrm{kPa})$. The data were fitted to the model of van Genuchten (1980), while the variables $\theta s$ and $\theta r$ were fixed with values of gravimetric water content corresponding to saturation and tension of $1500 \mathrm{kPa}$, respectively, both measured in the laboratory. The parameters $\alpha, m$ and $n$ were fitted using the Newton-Raphson iterative method, with dependence between $\mathrm{m}$ and $\mathrm{n}$.

\subsection{Analysis of Images}

For the analysis of images, undisturbed soil samples were carved with dimensions of $0.12 \times 0.07 \times 0.04 \mathrm{~m}$ in the layers of $0.0-0.12 \mathrm{~m}, 0.14-0.26 \mathrm{~m}$ and $0.30-0.42 \mathrm{~m}$ in each profile referring to the studied species. These samples were dried and impregnated with solution formed by polyester resin (Murphy, 1986), styrene monomer, catalyst (Ringrose-voase, 1991) and fluorescent pigment Tinopal OB (BASF®) (Murphy et al., 1977). After hardening, the impregnated blocks were cut and sandpapered. Random images (photomicrographs), $12 \times 15 \mathrm{~mm}\left(180 \mathrm{~mm}^{2}\right)$, were obtained for each vegetation cover of the agroforestry system and each depth. Total porosity was classified and quantified following the criteria defined by Cooper et al. (2005) and optimized through macros developed in Visual Basic language in Microsoft ${ }^{\circledR}$ Excel (Juhász et al., 2007).

The images were digitalized in $1024 \times 768$ pixels, with spectral resolution of 256 shades of gray, in $10 \times$ magnification, equaling a pixel to $156.25 \mu \mathrm{m}^{2}$. After the images with spectral resolution of 256 shades of gray were obtained, they were binarized. The pores in the images were identified using programming routines developed in the software Noesis ${ }^{\circledR}$ Visilog 5.4 according to Cooper et al. (2005).

\subsection{Statistical Analysis}

The data were subjected to analysis of variance (ANOVA), considering the completely randomized split-plot design, corresponding to three vegetation covers in main plots (L. leucocephala, P. pyramidalis and Zea mays), and four soil layers $(0.0-0.05,0.05-0.18,0.18-0.25$ and $0.25-0.41 \mathrm{~m})$ in sub-plots and four replicates. After verifying the normal distribution of the data through the Shapiro-Wilk test, the data were compared by the Scott-Knott test at 0.05 probability level.

\section{Results and Discussion}

\subsection{Soil Density and Soil-Air Intrinsic Permeability}

Soil density differed as a function of the factors of treatment (Figure 2). There was difference in response to the plant components in the superficial layer $(0.0-0.05 \mathrm{~m})$ and the highest value $\left(1540 \mathrm{~kg} / \mathrm{m}^{3}\right)$ was associated with Zea mays. Still in the superficial layer, the components $P$. pyramidalis and L. leucocephala resulted in lower values of soil density ( $1380 \mathrm{~kg} / \mathrm{m}^{3}$ and $1440 \mathrm{~kg} / \mathrm{m}^{3}$, respectively).

These Results agree with the higher contents of total organic carbon found superficially (Table 1), which indicate higher organic matter content, helping aggregation, increasing porosity and water infiltration, and reducing soil density (Szott, 1991). This is due to both the positive effect on soil structural stability and the fact that the organic material has low density, lower than that of mineral soil solids (Braida et al., 2006).

For the variations of soil density in the four layers (Figure 2), the lowest values were found in the superficial layer $(0.0-0.05 \mathrm{~m})$, ranging from 1380 to $1540 \mathrm{~kg} / \mathrm{m}^{3}$. In the deeper layers, the density was higher compared with the surface, but in the last layer $(0.25-0.41 \mathrm{~m})$, there was a reduction of soil density associated with the component Zea mays.

The lower values of soil density in the superficial layer associated with P. pyramidalis and L. leucocephala are due not only to the presence of the plant components, but also to the minimum soil disturbance in the influence area of these components. For having arboreal and arbustive sizes, these components contribute with the supply of organic matter, which in turn favors the aggregation, decreasing soil density (Romaneckas et al., 2009). It is worth highlighting the contribution of the porosity caused by the presence of roots and by the remarkable biological activity for the soil under these components, as visualized in the morphological description (Table 2). 


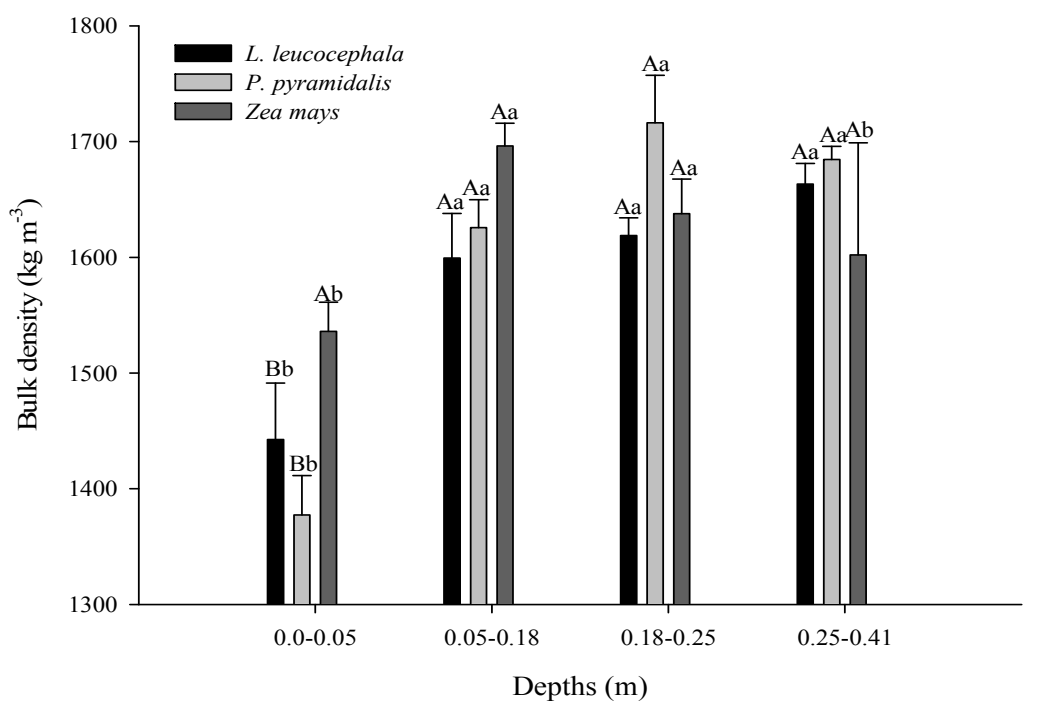

Figure 2. Soil density as a function of layers and plant components of the agrosilvopastoral system in the Brazilian semi-arid region. Means followed by the same letter, lowercase between layers and uppercase in the same layer, do not differ by Scott-Knott test at 0.05 probability level

Based on the chemical analysis performed to characterize the soil in the studied area, the contents of organic carbon in the superficial layer influenced by P. pyramidalis and L. leucocephala were higher in comparison to that observed in the area under the influence of Zea mays (Table 1). The increment of density as the soil depth increases is explained by the increase in the clay contents, as observed in the granulometric analysis, through the reduction of the organic matter content (Table 1), as well as through the structural changes that occur between the surface and subsurface horizons (subangular blocky to prismatic), as presented in the morphological description (Table 2).

The higher soil density observed in the superficial layer associated with the component Zea mays can be attributed to the entry of animals (goats and sheep) in the agrosilvopastoral system in the beginning of the dry period. These animals remain in the area for two hours a day, for 40 days, grazing crop residues. The negative effect of the grazing of crop residues indicates that the management was not adequate, as pointed out by Sulc $\&$ Franzluebbers (2014). Animal trampling tends to reduce soil porosity and increase soil density, favoring the compaction (Pei et al., 2008), causing first the destruction of macropores (Horn et al., 1995).

Regarding the soil-air intrinsic permeability (Table 3), the soil in the influence area of L. leucocephala and P. pyramidalis showed larger area available for gas flow, in comparison to the soil under the influence of Zea mays.

Table 3. Comparison of means of soil-air intrinsic permeability in the soil profiles under the influence of three plant components (Leucaena leucocephala, Poincianella pyramidalis and Zea mays) in an agrosilvopastoral system in the Brazilian semi-arid region

\begin{tabular}{ll}
\hline Plant component & $\log _{10} \mathrm{~K}_{\text {air }}\left(\mu \mathrm{m}^{2}\right)$ \\
\hline L. leucocephala & $1.46 \mathrm{a} \pm 0.019$ \\
P. pyramidalis & $1.51 \mathrm{a} \pm 0.019$ \\
Zea mays & $1.41 \mathrm{~b} \pm 0.024$ \\
\hline
\end{tabular}

Note. * Means followed by the same letter do not differ by Scott-Knott test at 0.05 probability level.

This is consistent with the lower values of soil density associated with the species of arboreal/arbustive size. Thus, the greater soil-air permeability associated with L. leucocephala and P. pyramidalis indicates that these plant components promote greater macroporosity.

\subsection{Soil-Water Characteristic Curve}

The soil-water characteristic curves in the influence area of the plant components of the agrosilvopastoral system in the layers of $0.0-0.05 \mathrm{~m}, 0.05-0.18 \mathrm{~m}, 0.18-25 \mathrm{~m}$ and $0.25-0.41 \mathrm{~m}$ are presented in Figure $3(\mathrm{a}, \mathrm{b}, \mathrm{c}$ and $\mathrm{d}$ ). 

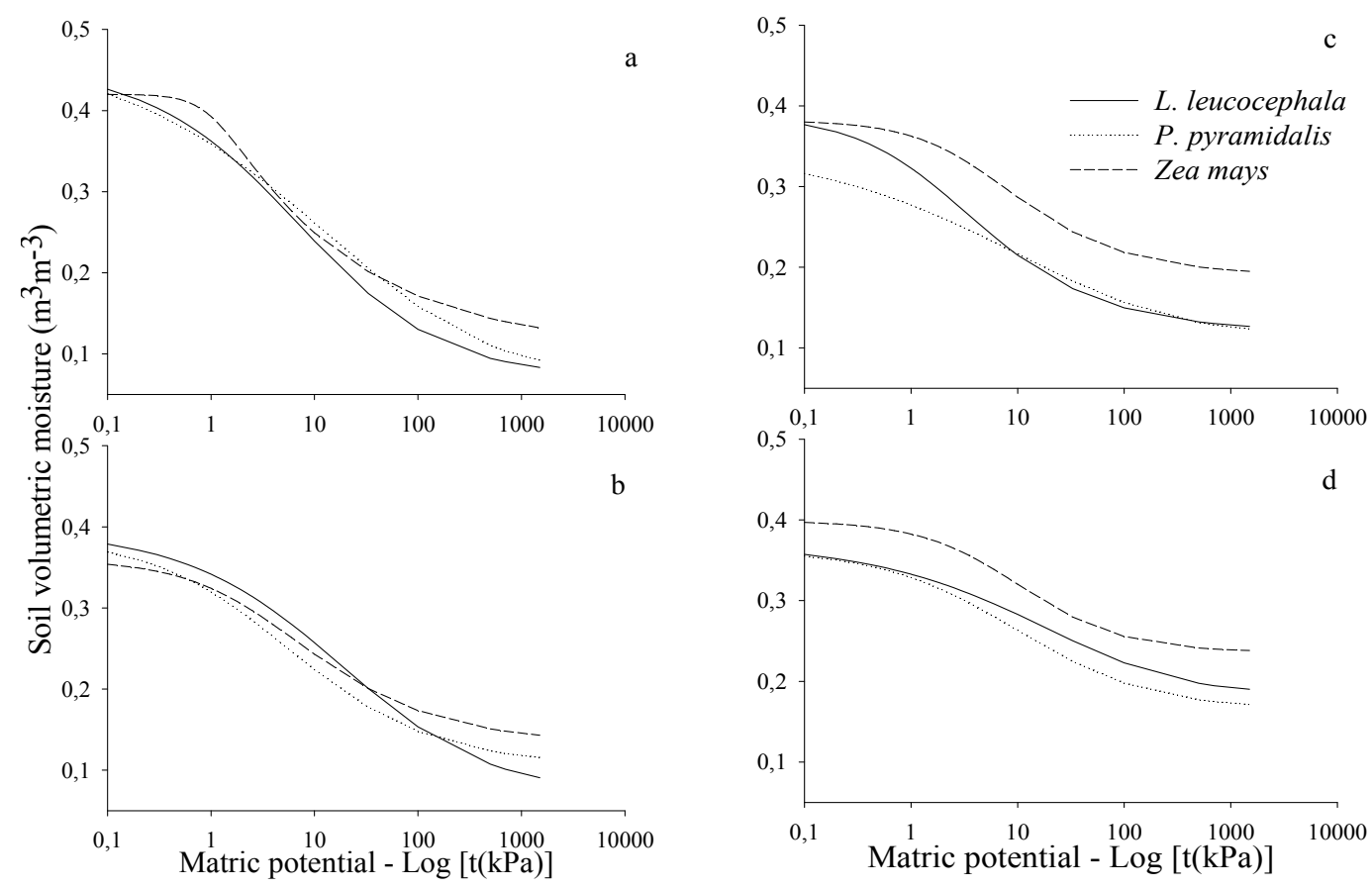

Figure 3. Soil-water characteristic curve of a Luvisol in the influence area of three plant components $(L$. leucocephala, P. pyramidalis and Zea mays) of an agrosilvopastoral system in the layers of 0.0-0.05 $\mathrm{m}$ (a), 0.05-0.18 $\mathrm{m}(\mathrm{b})$ 0.18-0.25 $\mathrm{m}(\mathrm{c})$ and $0.25-0.41 \mathrm{~m}(\mathrm{~d})$

In the layers of 0.0-0.05 and 0.05-0.18 m, there was a trend of higher water retention capacity in the soil under Zea mays, from the tension equivalent to field capacity on $(\sim 10 \mathrm{kPa})$. This can be advantageous, since it represents more water retained and available to the superficial root system of the crop. On the other hand, with intense rainfalls, this can represent higher risk of runoff formation and, consequently, of erosion in the upper layer.

At high matric potentials, the influence of macropores is greater (Rawls et al., 1991) and, in this case, the subangular blocky structure of the horizons (Table 2) suggests the presence of large-sized pores in this region. However, at lower potentials, in which the granulometric and mineralogical composition of the soil assumes greater importance due to its specific surface for the adsorption of water molecules (Gupta \& Larson, 1979), water retention is lower, in comparison to the deeper layers, because of the lower clay content present in these more-superficial horizons (Table 1).

In the surface layers mentioned in the last paragraph, the arrangement of the soil-water characteristic curves was typical of sandy soils (sandy loam texture, according to Table 2), with substantial part of the water drained already at the first tensions applied. This occurs due to the greater macroporosity, which promotes higher capacity of water infiltration in the soil.

The soil-water characteristic curves for L. leucocephala and P. pyramidalis in the superficial layer (0.0-0.05 m) were similar (Figure 3a), which can be attributed to the similarity in the distribution of the types and sizes of pores, as will be mentioned.

Similarity between the curves of L. leucocephala and P. pyramidalis was also observed in the layer of 0.25-0.41 $\mathrm{m}$ (Figure $3 \mathrm{~d}$ ). With the reduction of porosity and increase in soil density, the subsurface horizons $(0.18-0.25$ and $0.25-0.41 \mathrm{~m}$ ) showed high water retention capacity, especially at the highest tensions, decreasing the slope of the curve in relation to the matric potential axis. The smoothing of the first inflection that occurs in the subsurface horizons is attributed to the change in the type of pore, decrease of porosity and to the size of pores that favor water retention (Lewandowska et al., 2008).

Still based on soil-water characteristic curves, it is possible to verify the values of porosity in the condition of saturated soil-corresponding to total porosity. In the layer of 0.0-0.05 m, for all situations of plant components, the total porosity was approximately $43 \%$. In the layer of $0.05-0.18 \mathrm{~m}$, the observed values were 36,39 and $40 \%$ for the components Zea mays, P. pyramidalis and L. leucocephala, respectively. In the layer of $0.18-0.25 \mathrm{~m}$, the 
values of total porosity for the components P. pyramidalis, L. leucocephala and Zea mays were respectively equal to 32,38 and $38 \%$. Finally, in the deepest layer $(0.25-0.41 \mathrm{~m})$, the values of soil porosity were equal to 36 , 36 and $40 \%$ for the components P. pyramidalis, L. leucocephala and Zea mays, respectively.

\subsection{Analysis of Images}

The results of the analysis of images in the soil layers were presented in the form of histograms of distribution of the total area occupied by pores, according to their size and shape for each plant component (Figures 4, 5 and 6 ).

For all plant components, the largest area of pores was observed in the superficial layer $(0.0-0.12 \mathrm{~m})$. This is explained by the higher contents of organic matter in the surface layer of the soil under the influence of all studied components (Table 1). In addition, the greater porosity of the surface horizons is related to the smaller size of the structural units, which allows the formation of more pores in relation to what can be obtained in the subsurface horizons that have larger structural units (Baver et al., 1972).

The smaller structural units in the superficial soil layer are evidenced by the predominance of subangular blocks with small to medium size, while the prismatic structure with medium to large size prevailed in the subsurface horizons (Table 2). In addition, the distribution of particles that define the sandy loam textural class observed in surface also contributed to the presence of larger area of complex pores (packing type) (Table 2).

In the influence area of L. Leucocephala, the predominant porosity of the superficial soil layer (0.0-0.12 m) was complex-type and large-sized (Figure 4a). These pores reduce the physical limitations of the soil with respect to the mechanical resistance to penetration, favoring the growth of roots, which can increase the yield of the crops (Williams \& Weill, 2004).

In the layers of $0.14-0.26$ and $0.30-0.42 \mathrm{~m}$ (Figures $4 \mathrm{~b}$ and $4 \mathrm{c}$ ) of the profile under the influence of $L$. leucocephala, there was a reduction of the large and complex pores and increase in the area of rounded pores. Since there was a reduction of the large complex pores and increase in elongated and rounded pores, the behavior of the soil between surface and subsurface was altered, with change from a layer with lower soil-water retention capacity to another with higher soil-water retention capacity (Figures 3c and 3d).

As observed for the profile of L. leucocephala, the profile referring to P. pyramidalis had greater participation of large complex pores in surface (Figure 5a). However, this amount of pores was $40 \%$ lower than that in the profile of L. leucocephala. The higher porosity in surface found in the profile of L. leucocephala is attributed to the root density of the leguminous species, observed in the morphological description (Table 2).

In comparison to L. leucocephala, the porosity in the layer of $0.14-0.26 \mathrm{~m}$ of $P$. pyramidalis was higher, especially in the proportion of complex pores (Figure 5b). This higher porosity in subsurface can be attributed to the biological activity, evidenced by the presence of galleries and tubular pores filled with loose and microangular material (Table 2). It should be highlighted that there was presence of earthworms, which are able to positively influence structural and functional processes, including soil porosity (Al-maliki \& Scullion, 2013).

It is worth highlighting that in all components, highest soil porosity was found in surface $(0-12 \mathrm{~cm})$. The accumulation of plant residues on soil surface, due to the low mobilization, contributes to greater proliferation of roots in the superficial layers (Yibrin, Johnson, \& Eckert, 1993), and this greater predominance of roots in surface contributes with higher contents of organic matter and higher soil porosity.

Greater contribution of organic matter in surface, as found in the present study, also reinforces this result, given its participation in soil structuring. However, the granulometry inherent to the soil in surface, sandy loam, should not be disregarded, since it has major participation of macropores. This contributes to higher porosity, consequently greater water infiltration capacity and lower retention capacity. The structure in subangular blocks in surface, which lead to greater formation of pores between the structures, also agrees with this result.

In the subsurface of the soil under the influence of $P$. pyramidalis, besides the reduction of complex pores and increase of rounded pores, there was an increment of elongated pores. Expansion and contraction processes, resulting from rainy and dry periods, can be responsible for the presence of elongated pores. This occurs because these processes have a substantial effect on the arrangement of clays (Tessier et al., 1990), allowing a retraction of the mass of aggregates with the progressive loss of water, originating the elongated pores (Cherkov \& Ravina, 1999).

The presence of elongated pores can also be attributed to the biopores (biological cavities and channels), since roots and biological activity are the main responsible for the creation of continuous and elongated pores in the soil (Rodrigues et al., 2011). This evidences the biological activity, contributing to a better structure of the soil under the influence of $P$. pyramidalis. 
In the layer of $0.30-0.42 \mathrm{~m}$, there was a sharp reduction in the area of large complex pores (Figure $5 \mathrm{c}$ ), especially in comparison to the layer of $0.0-0.12 \mathrm{~m}$. This indicates that soils under the influence of $P$. pyramidalis also exhibit reduction in hydraulic conductivity and increase in water retention capacity in subsurface, which is consistent with the increase in density and reduction in the area available for air flow (Figure 2 and Table 3, respectively).

The reduction of large and complex pores from surface to subsurface indicates higher capacity of retention of water to plants in the subsurface soil layers, but also serves as an alert for the risks of water erosion, evidenced by the gradient of texture and structure. The reduction in water percolation increases the risks of forming runoff, which contributes to the transport phase of the erosive process.

The lowest porosity, in general, was found in the soil under the influence of Zea mays (Figure 6). This information is consistent with the higher values of density and lower soil-air intrinsic permeability (indicating smaller area available for gas flow), also found in the soil associated with this plant component.

The component Zea mays resulted in smaller area of elongated pores in all layers, compared with the other components (Figures 4, 5 and 6). As already mentioned, elongated pores are of transport (Pagliai et al., 1983) and their smaller area represents lower capacity of water transport for the soil under the influence of the annual crop. The complex porosity in the superficial layer $(0.0-0.12 \mathrm{~m})$ was also lower with Zea mays (Figure 6a), which leads to lower area of pores, also confirmed by the higher density and lower soil-air permeability (Figure 2 and Table 3).

It is important to mention that the values of total porosity obtained through the soil-water retention curve were higher than those obtained through the analysis of images. This occurs because of the dimensions considered in each technique, so that the total porosity (TP) based on the soil-water characteristic curve was obtained using the equation TP $=1$ - bulk density/particle density, while the determination of total porosity through the analysis of images refers to the two-dimensional projection of the pores on a plane (Moran et al., 1988), and their sizes represent only macro- and mesopores. However, despite the differences between the techniques, it is possible to relate them to the soil water retention (Bullock \& Thomasson, 1979). 


\section{Leucocephala}
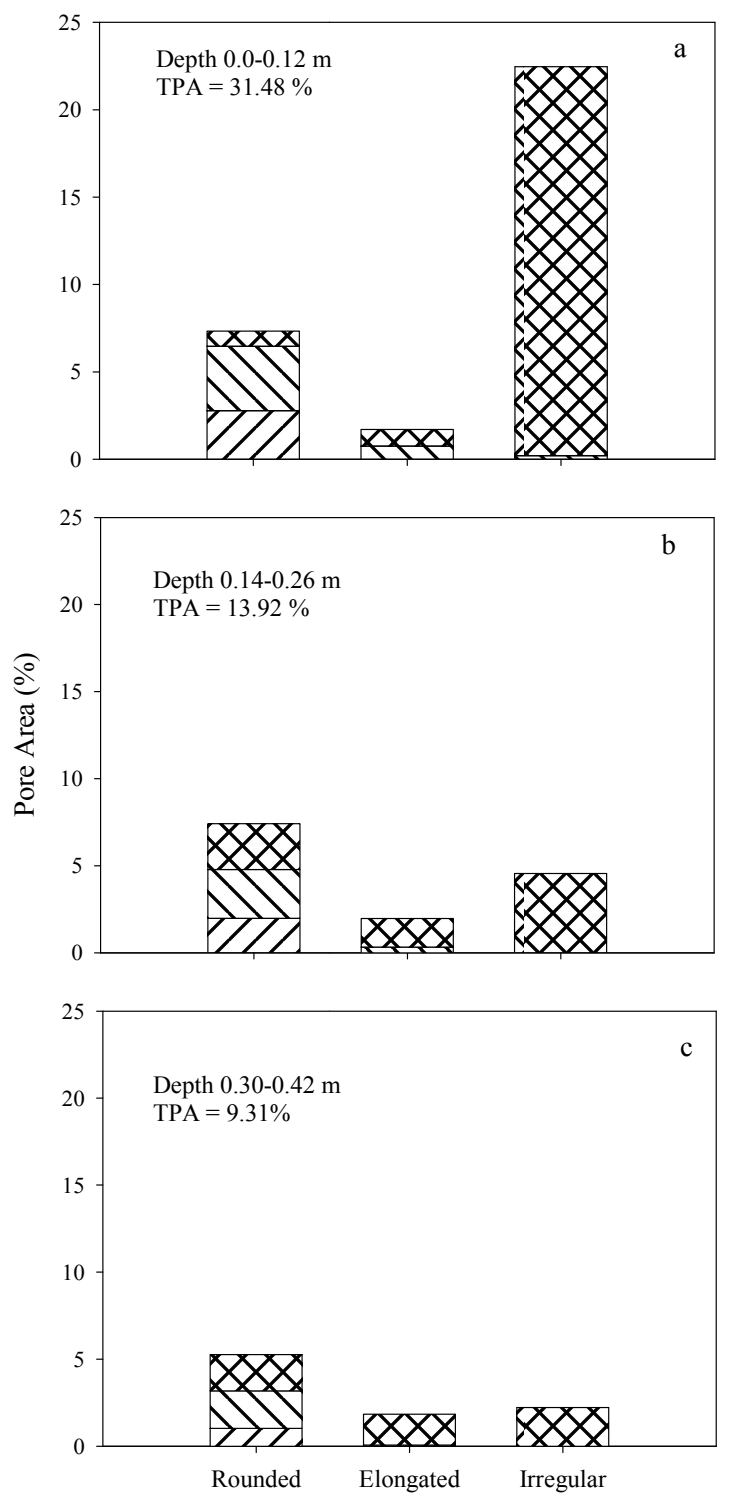

Small (0.001 to $\left.0.01 \mathrm{~mm}^{2}\right) \quad$ TPA $=$ Total percent of area $\square$ Medium (0.01 to $0.1 \mathrm{~mm}^{2}$ ) $\mathbf{D}$ Large $\left(>0.1 \mathrm{~mm}^{2}\right)$
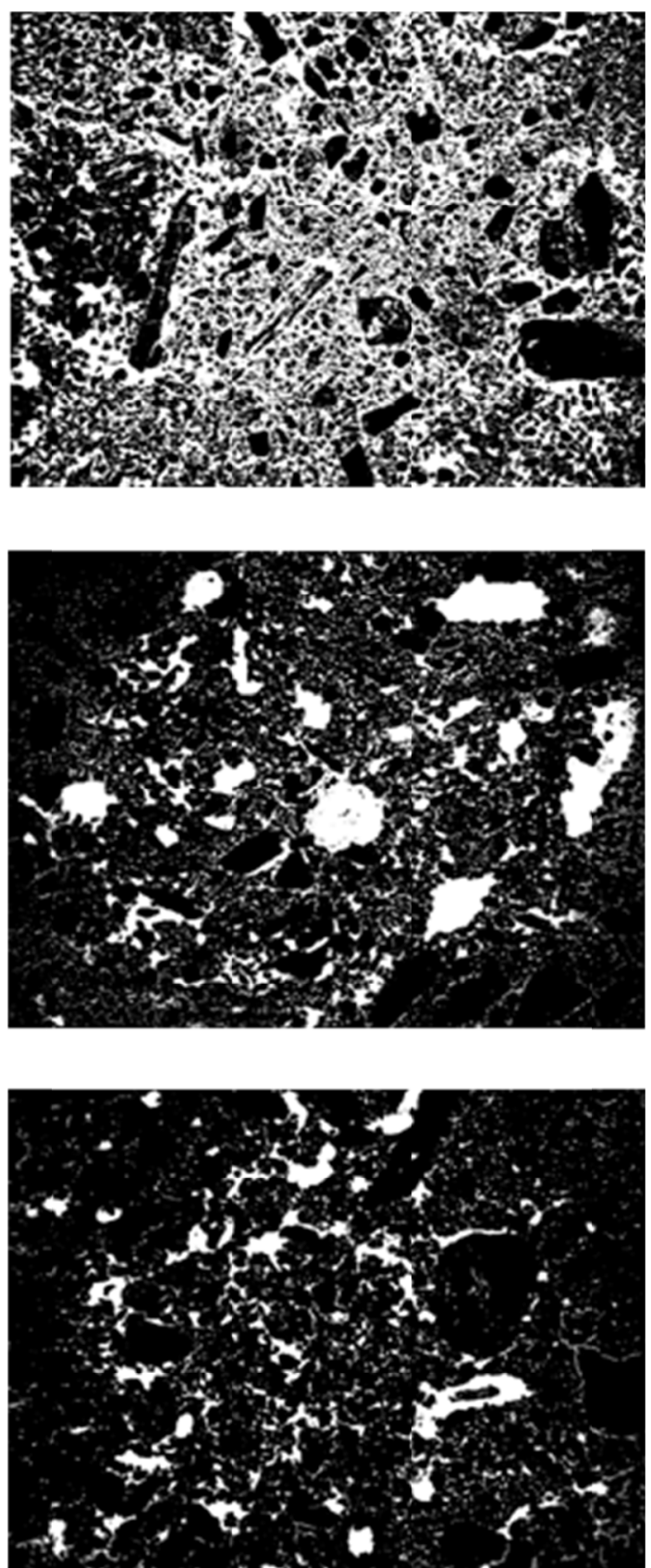

Figure 4. Porosity distribution based on pore shape (rounded; elongated; irregular) and size (small: 0.001-0.01 $\mathrm{mm}^{2}$, medium: 0.01-0.1 mm $\mathrm{mm}^{2}$, large: $\left.>0.1 \mathrm{~mm}^{2}\right)$ of three layers $(0.0-0.12 \mathrm{~m} \mathrm{(a)} ; 0.14-0.26 \mathrm{~m}(\mathrm{~b})$ and $0.30-0.42 \mathrm{~m}$

(c)) of a Luvisol in the influence area of $L$. leucocephala and the corresponding binary images. Pores are displayed in white and the solid phase in black 


\section{P. Pyramidalis}
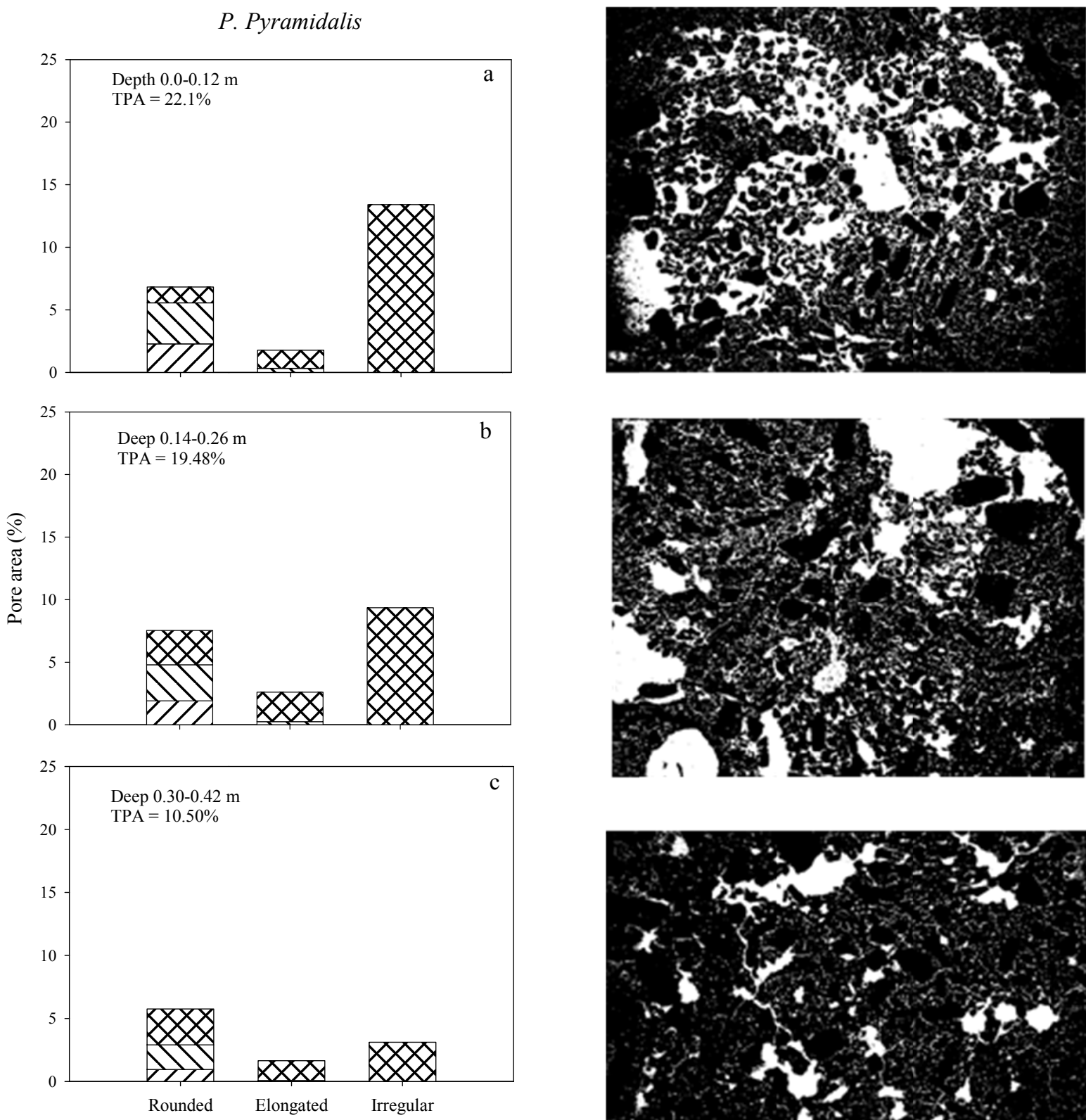

Small (0.001 to $\left.0.01 \mathrm{~mm}^{2}\right)$ TPA $=$ Total percent of area $\square$ Medium (0.01 to $\left.0.1 \mathrm{~mm}^{2}\right)$ М Large $\left(>0.1 \mathrm{~mm}^{2}\right)$

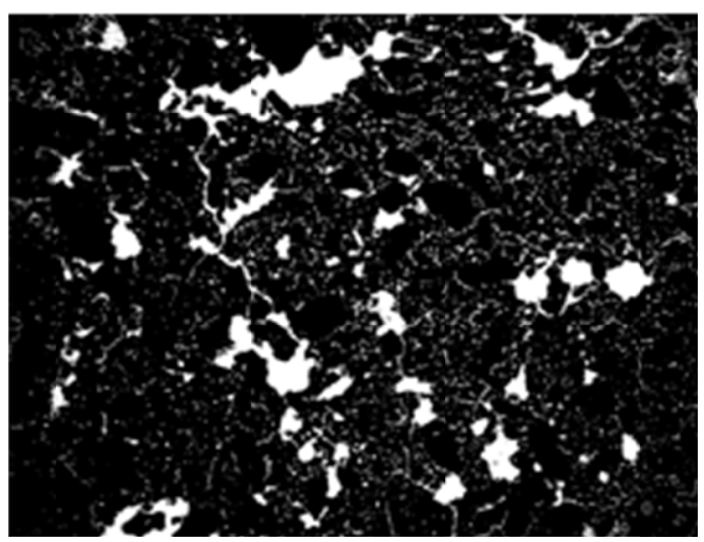

Figure 5. Porosity distribution based on pore shape (rounded; elongated; irregular) and size (small: 0.001-0.01 $\mathrm{mm}^{2}$, medium: 0.01-0.1 mm $\mathrm{mm}^{2}$, large: $\left.>0.1 \mathrm{~mm}^{2}\right)$ of three layers $(0.0-0.12 \mathrm{~m} \mathrm{(a)} ; 0.14-0.26 \mathrm{~m}(\mathrm{~b})$ and $0.30-0.42 \mathrm{~m}$

(c)) of a Luvisol in the influence area of $P$. pyramidalis and the corresponding binary images. Pores are displayed in white and the solid phase in black 
Zea mays
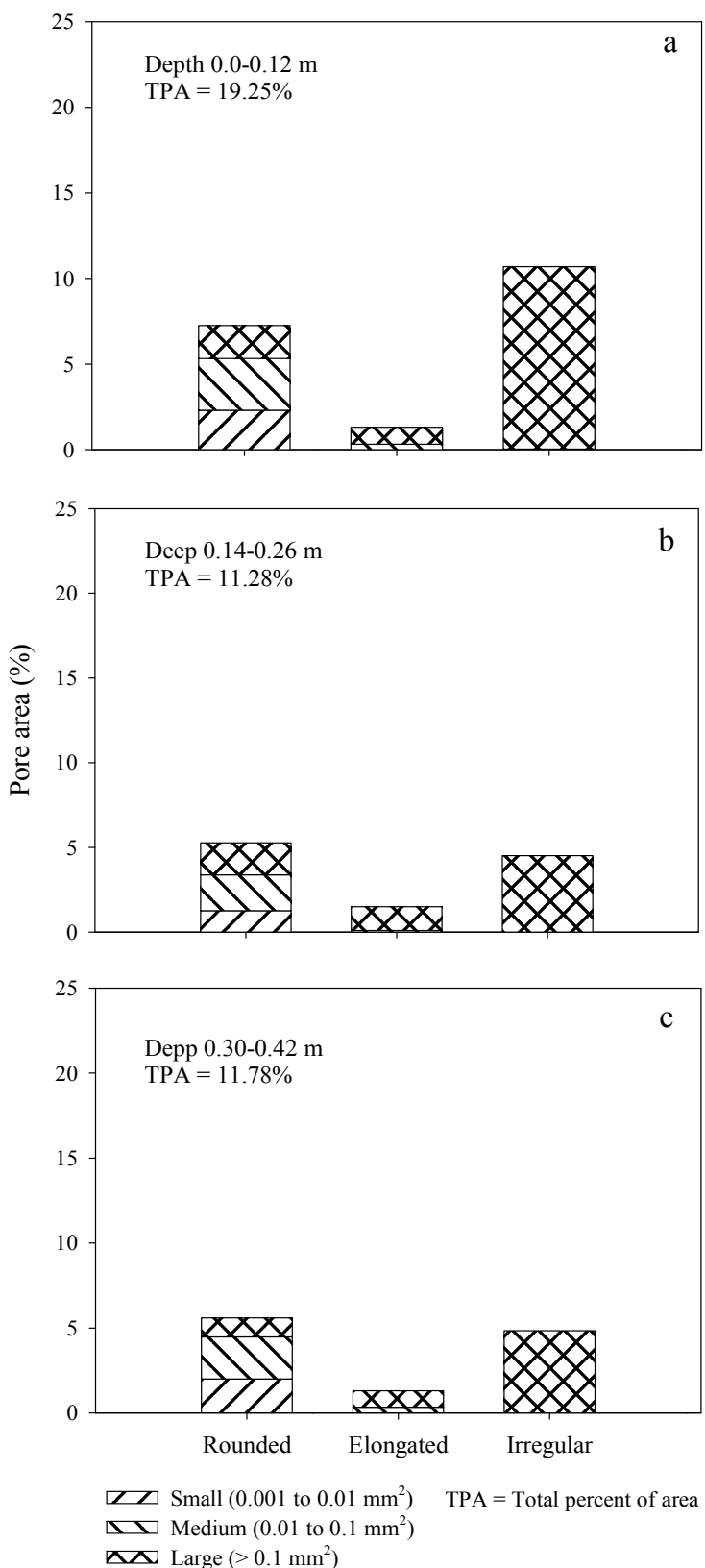
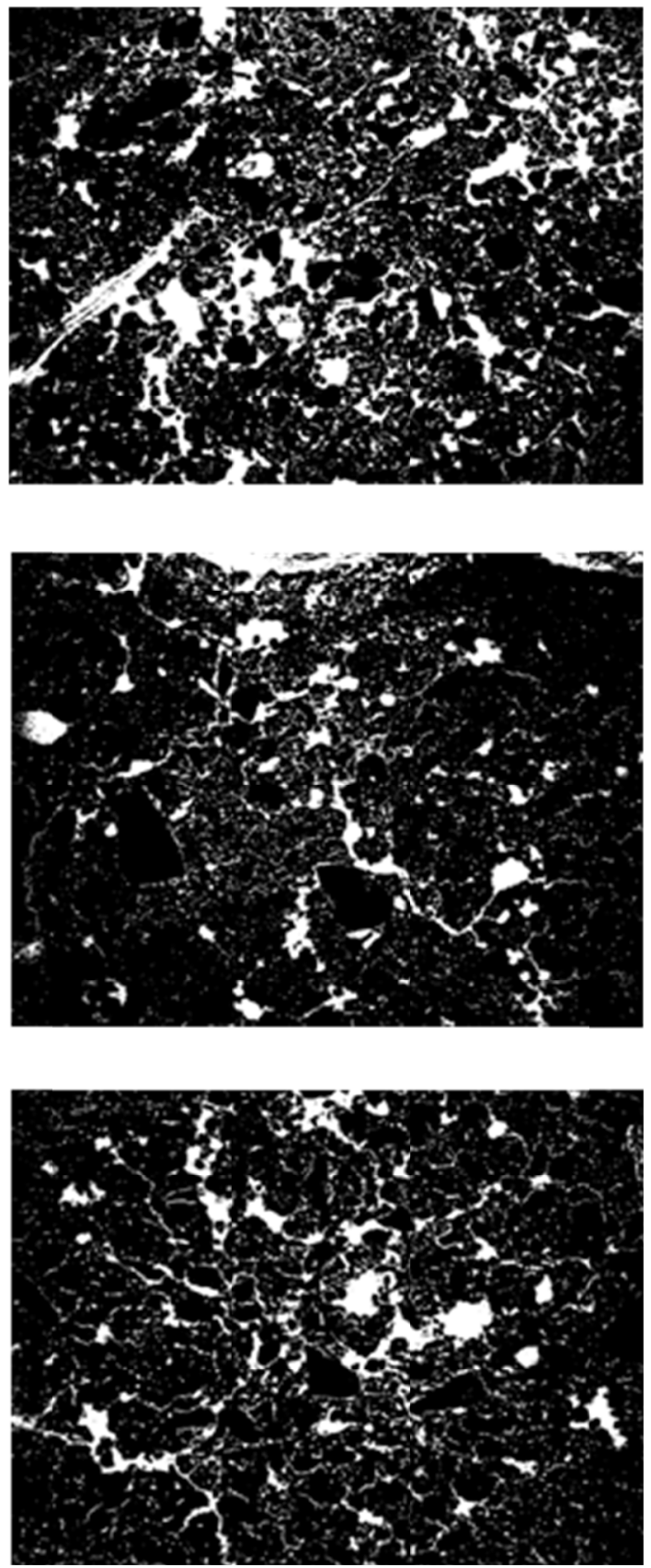

Figure 6. Porosity distribution based on pore shape (rounded; elongated; irregular) and size (small: 0.001-0.01 $\mathrm{mm}^{2}$, medium: $0.01-0.1 \mathrm{~mm}^{2}$, large: $\left.>0.1 \mathrm{~mm}^{2}\right)$ of three layers $(0.0-0.12 \mathrm{~m} \mathrm{(a)} ; 0.14-0.26 \mathrm{~m}$ (b) and $0.30-0.42 \mathrm{~m}$ (c)) of a Luvisol in the influence area of Zea mays and the corresponding binary images. Pores are displayed in white and the solid phase in black

\section{Conclusions}

The plant components of the agrosilvopastoral system promote differences in soil structure. The species $L$. leucocephala and $P$. pyramidalis result in better structure (higher porosity, permeability and better pore distribution), compared with Zea mays, especially in the superficial soil layers.

The plant components L. leucocephala and P. pyramidalis promote larger total area of pores and predominance of large complex pores. These pores function as alternative routes for root growth and favor water infiltration in the soil, contributing to soil and water conservation in the agrosilvopastoral system. 
The unfavorable result related to the component Zea mays is due not only to the characteristics of the plant species, but also to the form of management of the agrosilvopastoral system, in which there is grazing of crop residues. This requires the adjustment of the management with respect to the presence of animals in the area.

Based on the results, it is recommended to introduce arboreal and arbustive plant components such as $P$. pyramidalis and L. leucocephala to improve soil structure in soil conservation systems.

\section{Acknowledgements}

To CAPES (Brazilian Federal Agency for Support and Evaluation of Graduate Education) for granting the scholarship of the first author for the 'Pró-integração' project 55/2013. To the Laboratory of Micromorphology of Esalq-USP (LABMICRO).

\section{References}

Al-maliki, S., \& Scullion, J. (2013). Interactions between earthworms and residues of differing quality affecting aggregate stability and microbial dynamics. Applied Soil Ecology, 64, 56-62. https://doi.org/10.1016/ j.apsoil.2012.10.008

Baver, L. D., Gardner, W. H., \& Gardner, W. R. (1972). Soil physics (4th ed.). Wiley: New York.

Béliveau, A., Lucotte, M., Davidson, R., Paquet, S., Mertens, F., Passos, C. J., \& Romana, C. A. (2017). Reduction of soil erosion and mercury losses in agroforestry systems compared to forests and cultivated fields in the Brazilian Amazon. Journal of Environmental Management, 203, 522-532. https://doi.org/ 10.1016/j.jenvman.2017.07.037

Blake, G. R., \& Hartge, K. H. (1986). Bulk density. In A. Klute (Ed.), Methods Soil Analysis Part 1: Physical Mineralogical Methods (Agronomy Monography No. 9, 2nd ed., pp. 363-375). Madison: American Society of Agronomy, Soil Science Society of America.

Braida, J. A., Reichert, J. M., Veiga, M. D., \& Reinert, D. J. (2006). Resíduos vegetais na superfície e carbono orgânico do solo e suas relações com a densidade máxima obtida no ensaio Proctor. Revista Brasileira de Ciência do Solo, 30(4). https://doi.org/10.1590/S0100-06832006000400001

Bullock, P., \& Thomasson, A. J. (1979). Rothamsted studies of soil structure II. Measurement and characterisation of macroporosity by image analysis and comparison with data from water retention measurements. European Journal of Soil Science, 30(3), 391-413. https://doi.org/10.1111/j.1365-2389.1979. tb00997.x

Buyer, J. S., Baligar, V. C., He, Z., \& Arévalo-Gardini, E. (2017). Soil microbial communities under cacao agroforestry and cover crop systems in Peru. Applied Soil Ecology, 120, 273-280. https://doi.org/10.1016/ j.apsoil.2017.09.009

Chertkov, V. Y., \& Ravina, I. (1999). Morphology of horizontal cracks in swelling soils. Theoretical and Applied Fracture Mechanics, 31(1), 19-29. https://doi.org/10.1016/S0167-8442(98)00063-9

Cooper, M., Vidal-Torrado, P., \& Chaplot, V. (2005). Origin of microaggregates in soils with ferralic horizons. Scientia Agricola, 62(3), 256-263. https://doi.org/10.1590/S0103-90162005000300009

Duguma, L. A., \& Hager, H. (2011). Farmers' assessment of the social and ecological values of land uses in central Highland Ethiopia. Environmental Management, 47(5), 969-982. https://doi.org/10.1007/s00267011-9657-9

FAO. (2006). World reference base for soil resources 2006-A framework for international classification, correlation and communication. World Soil Resources Reports, 103, 128.

Gupta, S., \& Larson, W. E. (1979). Estimating soil water retention characteristics from particle size distribution, organic matter percent, and bulk density. Water Resources Research, 15(6), 1633-1635. https://doi.org/ 10.1029/WR015i006p01633

Horn, R., Domżżał, H., Słowińska-Jurkiewicz, A., \& Van Ouwerkerk, C. (1995). Soil compaction processes and their effects on the structure of arable soils and the environment. Soil and Tillage Research, 35(1-2), 23-36. https://doi.org/10.1016/0167-1987(95)00479-C

Ilstedt, U., Malmer, A., Verbeeten, E., \& Murdiyarso, D. (2007). The effect of afforestation on water infiltration in the tropics: A systematic review and meta-analysis. Forest Ecology and Management, 251(1), 45-51. https://doi.org/10.1016/j.foreco.2007.06.014 
Juhász, C. E. P., Cooper, M., Cursi, P. R., Ketzer, A. O., \& Toma, R. S. (2007). Savanna woodland soil micromorphology related to water retention. Scientia Agricola, 64(4), 344-354. https://doi.org/10.1590/ S0103-90162007000400005

Kirkham, D. (1947). Field method for determination of air permeability of soil in its undisturbed state. Soil Science Society of America Journal, 11(C), 93-99. https://doi.org/10.2136/sssaj1947.036159950011000 $\mathrm{C} 0018 \mathrm{x}$

Lewandowska, J., Tran Ngoc, T. D., Vauclin, M., \& Bertin, H. (2008). Water drainage in double-porosity soils: Experiments and micro-macro modeling. Journal of Geotechnical and Geoenvironmental Engineering, 134(2), 231-243. https://doi.org/10.1061/(ASCE)1090-0241(2008)134:2(231)

Moran, C. J., Koppi, A. J., Murphy, B. W., \& McBratney, A. B. (1988). Comparison of the macropore structure of a sandy loam surface soil horizon subjected to two tillage treatments. Soil Use and Management, 4(3), 96-102. https://doi.org/10.1111/j.1475-2743.1988.tb00743.x

Murphy, C. P. (1986). Thin Section Preparation of Soils and Sediments. AB Academic, Berkhamsted, UK.

Murphy, C. P., Bullock, P., \& Turner, R. H. (1977). The measurement and characterisation of voids in soil thin sections by image analysis. Part I. Principles and techniques. European Journal of Soil Science, 28(3), 498-508. https://doi.org/10.1111/j.1365-2389.1977.tb02258.x

Nguyen, Q., Hoang, M. H., Öborn, I., \& van Noordwijk, M. (2013). Multipurpose agroforestry as a climate change resiliency option for farmers: an example of local adaptation in Vietnam. Climatic Change, 117(1-2), 241-257. https://doi.org/10.1007/s10584-012-0550-1

Ola, A., Dodd, I. C., \& Quinton, J. N. (2015). Can we manipulate root system architecture to control soil erosion? Soil, 1(2), 603-612. https://doi.org/10.5194/soil-1-603-2015

Paciullo, D. S. C., de Miranda Gomide, C. A., de Castro, C. R. T., Fernandes, P. B., Müller, M. D., Pires, M. D. F. Á., ... Xavier, D. F. (2012). Características produtivas e nutricionais do pasto em sistema agrossilvipastoril, conforme a distância das árvores. Pesquisa Agropecuária Brasileira, 46(10), 1176-1183. https://doi.org/ 10.1590/S0100-204X2011001000009

Pagliai, M., LaMarca, M., \& Lucamante, G. (1983). Micromorphometric and micromorphological investigations of a clay loam soil in viticulture under zero and conventional tillage. European Journal of Soil Science, 34(2), 391-403. https://doi.org/10.1111/j.1365-2389.1983.tb01044.x

Pagliai, M., Pezzarossa, B., Mazzoncini, M., \& Bonari, E. (1989). Effects of tillage on porosity and microstructure of a loam soil. Soil Technology, 2(4), 345-358. https://doi.org/10.1016/0933-3630(89) 90002-0

Pei, S., Fu, H., \& Wan, C. (2008). Changes in soil properties and vegetation following exclosure and grazing in degraded Alxa desert steppe of Inner Mongolia, China. Agriculture, Ecosystems \& Environment, 124(1), 33-39. https://doi.org/10.1016/j.agee.2007.08.008

Pires, L. F., Borges, J. A., Rosa, J. A., Cooper, M., Heck, R. J., Passoni, S., \& Roque, W. L. (2017). Soil structure changes induced by tillage systems. Soil and Tillage Research, 165, 66-79. https://doi.org/10.1016/ j.still.2016.07.010

Rawls, W. J., Gish, T. J., \& Brakensiek, D. L. (1991). Estimating soil water retention from soil physical properties and characteristics. Advances in Soil Science, 16, 213-234. https://doi.org/10.1007/978-1-46123144-8_5

Ringrose-Voase, A. J. (1991). Micromorphology of soil structure-description, quantification, application. Australian Journal of Soil Research, 29(6), 777-813. https://doi.org/10.1071/SR9910777

Romaneckas, K., Romaneckienė, R., Šarauskis, E., Pilipavičius, V., \& Sakalauskas, A. (2009). The effect of conservation primary and zero tillage on soil bulk density, water content, sugar beet growth and weed infestation. Agronomy Research, 7(1), 73-86.

Salako, F. K., \& Kirchhof, G. (2003). Field hydraulic properties of an Alfisol under various fallow systems in southwestern Nigeria. Soil Use and Management, 19(4), 340-346. https://doi.org/10.1111/j.1475-2743.2003. tb00324.x

Silva, G. L., Lima, H. V., Campanha, M. M., Gilkes, R. J., \& Oliveira, T. S. (2011). Soil physical quality of Luvisols under agroforestry, natural vegetation and conventional crop management systems in the Brazilian semi-arid region. Geoderma, 167, 61-70. https://doi.org/10.1016/j.geoderma.2011.09.009 
Stoops, G. (2003). Guidelines for analysis and description of soil and regolith thin sections. Soil Science Society of America Inc.

Sulc, R. M., \& Franzluebbers, A. J. (2014). Exploring integrated crop-livestock systems in different ecoregions of the United States. European Journal of Agronomy, 57, 21-30. https://doi.org/10.1016/j.eja.2013.10.007

Szott, L. T., Fernandes, E. C., \& Sanchez, P. A. (1991). Soil-plant interactions in agroforestry systems. Forest Ecology and Management, 45(1-4), 127-152. https://doi.org/10.1016/0378-1127(91)90212-E

Tessier, D., Beaumont, A., \& Pedro, G. (1990). Influence of clay mineralogy and rewetting rate on clay microstructure. Developments in Soil Science, 19, 115-121. https://doi.org/10.1016/S0166-2481(08)70322-2

van Genuchten, M. T. (1980). A closed-form equation for predicting the conductivity of unsaturated soils. Soil Science Society of America Journal, 44(5), 892-897. https://doi.org/10.2136/sssaj1980.036159950044000 $50002 \mathrm{x}$

van Oudenhoven, A. P., Veerkamp, C. J., Alkemade, R., \& Leemans, R. (2015). Effects of different management regimes on soil erosion and surface runoff in semi-arid to sub-humid rangelands. Journal of Arid Environments, 121, 100-111. https://doi.org/10.1016/j.jaridenv.2015.05.015

Verheye, W. H. (2009). Land Use, Land Cover and Soil Sciences-Volume IV: Land Use Management and Case Studies. EOLSS Publications.

Williams, S. M., \& Weil, R. R. (2004). Crop cover root channels may alleviate soil compaction effects on soybean crop. Soil Science Society of America Journal, 68(4), 1403-1409. https://doi.org/10.2136/ sssaj2004.1403

Yibirin, H., Johnson, J. W., \& Eckert, D. J. (1993). No-till corn production as affected by mulch, potassium placement, and soil exchangeable potassium. Agronomy Journal, 85(3), 639-644. https://doi.org/10.2134/ agronj1993.00021962008500030022x

\section{Copyrights}

Copyright for this article is retained by the author(s), with first publication rights granted to the journal.

This is an open-access article distributed under the terms and conditions of the Creative Commons Attribution license (http://creativecommons.org/licenses/by/4.0/). 